\title{
The Chinese national emergency medical rescue team response to the Sichuan Lushan earthquake
}

\author{
Jun Yang • Jinhong Chen $\cdot$ Huiliang Liu $\cdot$ Kai Zhang • \\ Wei Ren $\cdot$ Jingchen Zheng
}

Received: 21 May 2013/Accepted: 10 June 2013/Published online: 21 June 2013

(C) The Author(s) 2013. This article is published with open access at Springerlink.com

\section{Introduction}

At 8:02 on 20 April 2013, an earthquake of magnitude 7.0 struck the Lushan area of Sichuan province, China. The affected population was 1.99 million, spread over 19 cities involving 115 countries. Over 458,000 people were resettled urgently (http://zh.wikipedia.org/wiki/ 2013 Yaanearthquake). The number of those injured and killed is reported to be 13,000 and 196 by the time 12:00, 26 April (http://news.sina.com.cn/c/2013-04-27/090126968052.shtml). The decision to set out an emergency medical rescue team was taken at a national level the Ministry of Health, and the immediate response was funded by The General Hospital of the Chinese People's Armed Police Forces. The request to the medical team came through $2 \mathrm{~h}$ after the earthquake, and the team arrived at Yaan People's Hospital with medicine and equipment $14 \mathrm{~h}$ later. This paper describes the team's experience during the immediate aftermath of the earthquake and the following 8 days.

This is a special project of National Health Industry Research (201302003). The team members of this project are Jingchen Zheng, Huiliang Liu, Kai Zhang, Jinghong Chen, Wei Ren, Jun Yang, Chengxin Han, Mei Xi, Chuan Jiang, Chengwei Zhang, Yaohui Feng, Lizhi Ma, Weiqiang Zhang, Ruijing Meng, Ying Cheng, Fulang Jing, Han Zhang and Jiangpeng Cui.

J. Yang

Critical Care Medicine Department, The General Hospital of the Chinese People's Armed Police Forces, Beijing 100039, China

J. Chen · K. Zhang $\cdot$ W. Ren · J. Zheng $(\bowtie)$

Institute of Disaster Relief Medical Science, The General Hospital of the Chinese People's Armed Police Forces, Yongding Road, No. 69, Haidian District, Beijing 100039, China

e-mail: zhengjingchen@126.com

H. Liu

Cardiology Department, The General Hospital of the Chinese People's Armed Police Forces, Beijing 100039, China 


\section{Immediate response post earthquake}

According to previous earthquake medical rescue experience in China (Lu-Ping et al. 2012; Qiu et al. 2010), peripheral limb fracture, head injury and soft tissue contusions would be the principal problems, and a neurosurgery, a general surgery, a thoracic surgery, and two orthopaedic surgeons formed the core of the initial team. These were supported by an anaesthetist, an ultrasound technician, three physicians (one gastroenterology, two respiration), a paediatrician, three ICU/CCU physicians and two emergency nurse who could triage patients, provide immediate care and treatment and assist in the operating theatre. Anaesthetic support was also assisted by local anaesthetists. An epidemiologist and two logistics personnel completed the team to prevent from putting burden on local material supplies.

The team landed on Chengdu Shuangliu Airport at 20:00 and went to Yanan People's Hospital by bus, the nearest hospital to the epicentre that had functioning surgical facilities $130 \mathrm{~km}$ away from the airport. As for the traffic of Cheng-Ya Highway was well, we arrived at the hospital in $2 \mathrm{~h}$ and then began work (Fig. 1). As expected, extremity injuries and head injury were the most common injury encountered, in keeping with the usual pattern of injury seen in survivors of major earthquakes (Qiu et al. 2010; Salimi et al. 2009; Mohebbi et al. 2008).

\section{The work of the team in Yaan}

Although, according to the writer's observation and news reports, about nearly all health facilities in the affected area suffered damage in different degree, but the loss of local health staff was not reported and the major advanced hospitals and their facilities were not devastated (such as Lushan People's Hospital, Baoxing Hospital, and Yaan People's Hospital) (http://society.people.com.cn/n/2013/0421/c1008-21221708.html). They quickly reorganized and began to provide services after the disaster. With the available of electricity on 21 April 2013, Baoxing Hospital had recovered its surgical ability (http://news. ifeng.com/mainland/special/lushandizhen/content-3/detail_2013_04/22/24496736_0.shtml).

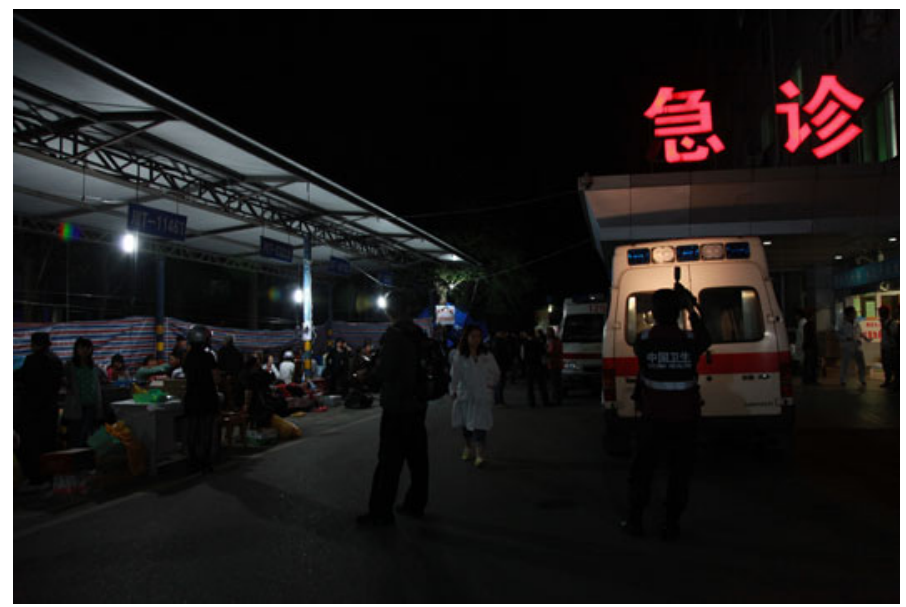

Fig. 1 Yaan People's Hospital where NEMRT worked 
In order to prevent hospital overload, a wide patients' distribution system was set up. Serious injuries were transported to West China Hospital and Sichuan People's Hospital in Chengdu $113 \mathrm{~km}$ away from the epicentre. And because of the greater number of local surgeons and relatively minor injuries in Yaan, our surgeons usually worked alongside Sichuan colleagues. But our CCU and ICU physicians managed several serious mortal heart, respiratory and cerebral emergency patients' treatment, which was different from previous experiences.

The team reviewed with the local colleagues over 550 cases, either immediately post injury or earthquake-associated emergency diseases. On day one, for example, the team carried out PTCA (percutaneous transluminal coronary angioplasty) of a severe stenosis of the LAD (left anterior descending artery) for a 65-year-old man transported from Tianquan who suffered from AMI (acute myocardial infarction) (Fig. 2).

CPCR (cardiopulmonary-cerebral resuscitation) was another typical emergency treatment had been carried out in a 28 -year-old man evacuated from Lushan who suffered from AWO (airway obstruction) and cardiac arrest (Fig. 3).

The aftershock added further to landslide and road collapse; the road accessing to Baoxing were often cut off. Further more, some towns and villages scattered in mountains between Lushan and Baoxing had lost telecommunication at that time. These factors meant that some of the victims, especially those far away from countries or highways, should be waiting for rescue aid. So the team decided to send out medical rescue unit with basic medicine and equipments by ambulances to these areas to provide medical aid and transportation. The team visited Yuxi of Baosheng Township, Renjia of Shuangshi Township and Baoxing. Ultimately, the team treated 1,143 cases and transported seven cases to Yaan People's Hospital or Affiliated Hospital of West China University of Medical Sciences, including 1 UGB (upper gastrointestinal haemorrhage), 1 pesticide intoxication by mistake, 4 lower extremity fracture ( 1 fracture of left ankle, 2 fracture of right tibia and 1 fracture of left intertrochanteric fracture) and 1 lumbar injury.

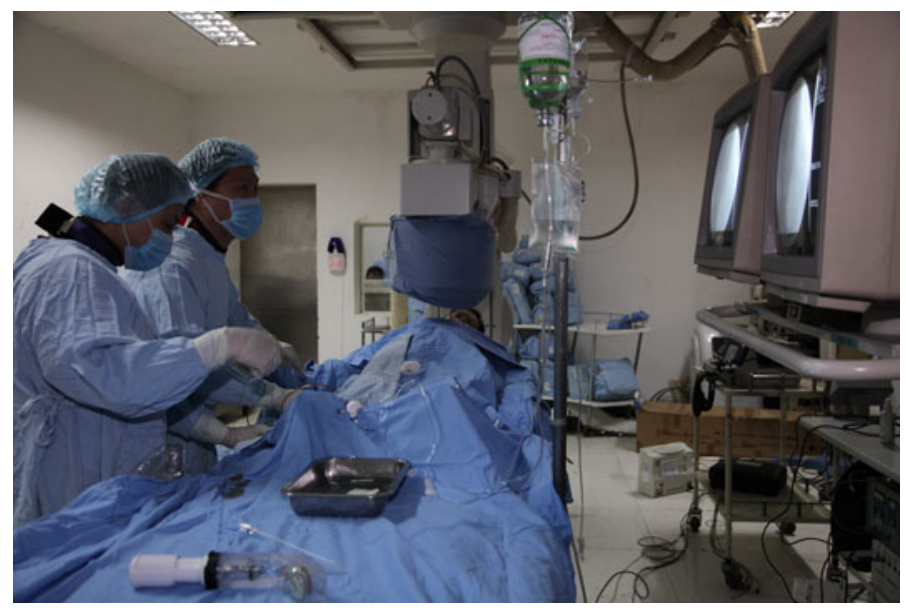

Fig. 2 Mr. Huiliang Liu (right first) and Mr. Haibo Zhang carrying out PTCA (percutaneous transluminal coronary angioplasty) of a severe stenosis of the LAD (left anterior descending artery) in Yaan People's Hospital 


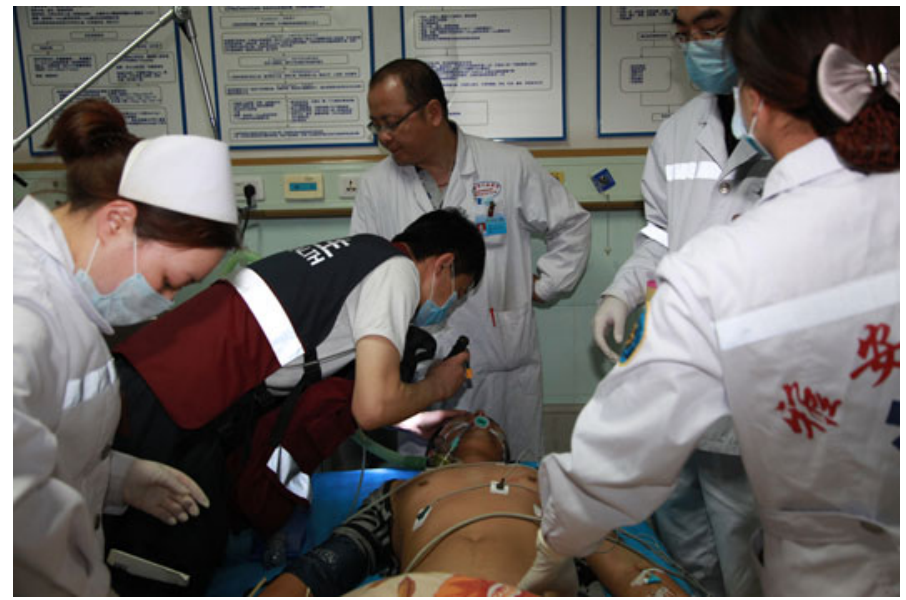

Fig. 3 Mr. Jun Yang (left second) rescuing an AWO (airway obstruction) and cardiac arrest with local emergency colleagues of Yanan People's Hospital

\section{Injured patient}

By now, neither national institution nor individual hospitals have published injury data. So there is only a sample study of patients across two countries (Baoxing, Lushan) based on our team records from 20 April 2013 to 27 April 2013. This identified 329 victims with full information. The extremity injuries account for $38.9 \%$ (128), and fractures account for $17.0 \%$ (56), just $62.5 \%$ (35) of which were lower extremity fracture. Traumatic head injury occurred in $112(33.4 \%)$, and serious head injuries account for $4.6 \%$ (15).

There were $44(13.4 \%)$ cases of spinal cord injury recorded by us after the earthquake, with $93.2 \%$ (41) were directly caused by the earthquake, and some patients got injured when they jumped from buildings or took other dangerous ways to escape the earthquake or after shock occurred. Spinal cord injuries were mostly at thoracic level and below which account for $86.4 \%$ (38), indicating that patients with higher lesions generally died before or shortly after rescue. This character also was recorded by other researchers in 2008 Wenchuan earthquake (Dong et al. 2009).

Crush syndrome occurred in $1(0.3 \%)$ according to our record. However, in Chengdu, to where many patients had been transported, the incidence has not been reported. The incidence probably higher than that we observed. In other studies, the incidence of Crush syndrome rages from 3.9 to $5.4 \%$ (Yang et al. 2009; Oda et al. 1997).

\section{Conclusion}

In 2008, Wenchuan area, $85 \mathrm{~km}$ away from Lushan, was struck by a magnitude 8.0 earthquake. Approximately 69,227 people were killed, 17,923 missing and 374,643 were injured. In an effort to learn from this catastrophic experience, in 2010, the Ministry of Health, organized medical rescue teams specializing in disaster medicine, called national emergency medical rescue teams (NEMRTs). By the end of 2012, there have been 22 NEMRTs scattered in 20 provinces and cities. These teams are developed during the acute disaster phase, not only for natural disasters, but also for disasters such as airplane accidence and public health 
incidence. Local governor can activate NEMRTs depending on the magnitude of the disaster. Local governments also built up local emergency rescue teams based on medical and fire fighting institutions. Immediately after Lushan earthquake on 20 April 2013, NEMRTs throughout the nation were activated. In addition to the NEMRTs, Sichuan Health Department, military medical teams and other organizations sent out medical teams to affected areas. Within the first $12 \mathrm{~h}$, more than 136 local rescue teams and 982 medical professionals had carried out medical relief at disaster base hospitals in the Lushan area (http://www. scwst.gov.cn/index.php/gzkb/5816-2013-04-20-14-58-08).

Past observations of earthquakes indicated that rapid extrication and treatment are critical for the patients' survival in emergency settings (Ashkenazi et al. 2005). The immediate needs of disaster victims must be met within hours of disaster impact. Based on the previous disaster relief experience and national plan, the local rescue teams and medical authorities rapidly organized and began to self-relief. By the time of our arrival (14 $\mathrm{h}$ after the earthquake), they had set up an effective triage, transport and treatment corridor. They have retrieved and treated 6,492 victims, transported 974 injuries to Chengdu in less than $13 \mathrm{~h}$ (http://www.scwst.gov.cn/index.php/gzkb/5816-2013-04-20-1458-08). And the critical electricity supply and traffic to Lushan recovered (http://news. sina.com.cn/c/2013-04-20/170026890577.shtml; http://news.xinhuanet.com/2013-04/22/c_ 124610222.htm; http://news.xinhuanet.com/politics/2013-04/20/c_115469679.htm). Their rapidly and effectively work lowered the mortality of the disaster.

Although the severe injuries were transported to Chengdu for advanced treatment, and there were greater number of local surgeons, most time we worked alongside them. But there had been a clear request by the local colleagues for our support to rescue and stabilize these serious emergency patients after the earthquake. To broaden its impact beyond immediate patient care, the team provided wider technical support and build a relationship with local colleagues that would lead to a sharing of knowledge and experience that could benefit major incident responses in the future. It is believed that this has been achieved.

Acknowledgments Fund provided by The General Hospital of the Chinese People's Armed Police Forces.

Open Access This article is distributed under the terms of the Creative Commons Attribution License which permits any use, distribution, and reproduction in any medium, provided the original author(s) and the source are credited.

\section{References}

Ashkenazi I, Isakovich B, Kluger Y et al (2005) Prehospital management of earthquake casualties buried under rubble. Prehosp Disast Med 20(2):122-133

Dong Z, Yang Z, Chen T et al (2009) Spinal injuries in the Sichuan earthquake. N Engl J Med 361(6):636-637

http://news.ifeng.com/mainland/special/lushandizhen/content-3/detail_2013_04/22/24496736_0.shtml. Accessed 22 Apr 2013

http://news.sina.com.cn/c/2013-04-27/090126968052.shtml. Accessed 27 Apr 2013

http://news.sina.com.cn/c/2013-04-20/170026890577.shtml. Accessed 21 Apr 2013

http://news.xinhuanet.com/2013-04/22/c_124610222.htm. Accessed 23 Apr 2013)

http://news.xinhuanet.com/politics/2013-04/20/c_115469679.htm. Accessed 22 Apr 2013)

http://society.people.com.cn/n/2013/0421/c1008-21221708.html (accessed 6 May 2013)

http://www.scwst.gov.cn/index.php/gzkb/5816-2013-04-20-14-58-08. Accessed 6 May 2013

http://zh.wikipedia.org/wiki/2013 Yaanearthquake. Accessed 4 May 2013

Lu-Ping Z, Rodriguez-Llanes JM, Qi W et al (2012) Multiple injuries after earthquakes: a retrospective analysis on 1, 871 injured patients from the 2008 Wenchuan earthquake. Crit Care 16(3):1-9 
Mohebbi HA, Mehrvarz S, Saghafinia M et al (2008) Earthquake related injuries: assessment of 854 victims of the 2003 Bam disaster transported to tertiary referral hospitals. Prehospital Disast Med 23(6):510 515

Oda J, Tanaka H, Yoshioka T et al (1997) Analysis of 372 patients with crush syndrome caused by the Hanshin-Awaji earthquake. J Trauma Acute Care Surg 42(3):470-476

Qiu J, Liu G, WANG S et al (2010) Analysis of injuries and treatment of 3401 inpatients in 2008 Wenchuan earthquake_-based on Chinese Trauma Databank. Chin J Traumatol (English Edition) 13(5):297-303

Salimi J, Abbasi M, Khaji A et al (2009) Analysis of 274 patients with extremity injuries caused by the Bam earthquake. Chin J Traumatol (English Edition) 12(1):10-13

Yang C, Wang H, Zhong $\mathrm{H}$ et al (2009) The epidemiological analyses of trauma patients in Chongqing teaching hospitals following the Wenchuan earthquake. Injury 40(5):488-492 